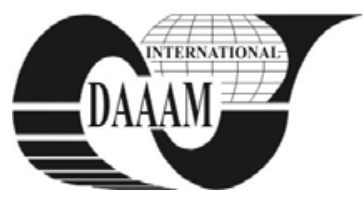

Annals of DAAAM for 2011 \& Proceedings of the 22nd International DAAAM Symposium, Volume 22, No. 1, ISSN 1726-9679 ISBN 978-3-901509-83-4, Editor B. Katalinic, Published by DAAAM International, Vienna, Austria, EU, 2011 Make Harmony between Technology and Nature, and Your Mind will Fly Free as a Bird

\title{
AUTOMATIC GRIPPER EXCHANGE IN INTELLIGENT MANUFACTURING SYSTEMS
}

\author{
KERAK, P[eter] \& HOLUBEK, R[adovan]
}

\begin{abstract}
Robot grippers are an integral part in technological operations. Their role is to provide a clamp, the most accurate positioning and centering of the workpieces. In this article is described an automated end effector exchange system - AHC. This system is powered by pressed air and the correct binding between AHC unit and gripper with flange are realized by conical shape in the unit adapter. In many cases we need to use two, three or more different end effectors. Due to the increasing end effector changing process effectivity several types of end effector exchange mechanisms are developed.

Key words: grippers, automatic exchange, manipulation, robot gripper, intelligence
\end{abstract}

\section{INTRODUCTION}

Each industrial robots and production system currently has integrated itself a certain degree of intelligence. Intelligence in production systems is mainly consisted of sensory equipment and control systems (Mudrikova et al., 2009). They are usually equipped by set of sensors for information collecting from its environment and by several actuators to operations realization. The todays trend in the field of end effector exchange is the automated exchange systems (Danisova et al., 2011). Automatic exchange systems are used for gripping jaws exchange also.

\section{GRIPPERS EXCHANGE POSSIBILITIES}

The increasing claim of robotized workplace flexibility require that robots use more than one gripper. One robot can realize several different operations and for each of them must use the proper gripper (Matusova \& Javorova 2008). This request causes the claim to gripper exchanging efficiency. We can realize this exchange by several modes.

- Manual exchange - simple solution, but low flexibility, time and cost expensive solution, possible dificultnes in case when we need use sensors at grippers. The operator must go into robots working area and this is potentially hazardous.. This kind of gripper exchange is not suitable for production systems.

- Automated exchange - changing is realized by commands of robots control system. The automated griper exchange is possible divided into three groups: - multi launching grippers using,

- whole gripper exchange,

- clamping pads using (Kostal et al., 2008).

The exchange mechanism between a robotic arm and a gripper must allow what fellows:

- mechanical bind - forces and torques transmission,

- $\quad$ energetic bind - power supplies to actuators and sensors in gripper,

- data bind - data transfer between the gripper and control system,
- material flow bind - in some cases when the material flow is realized through a gripper (screw feeding for a screwing end effectors) (Danisova et al., 2009).

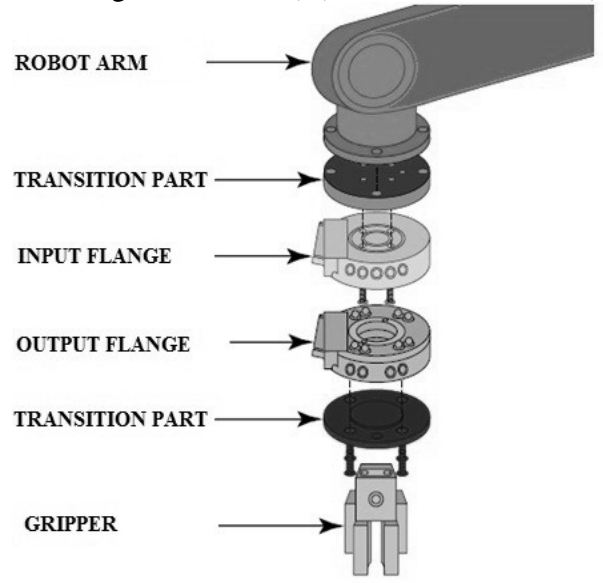

Fig. 1. Example of the automatic exchange gripper to robot arm

The exchange operation is controlled by robots control system (Velisek et al., 2008). At Fig.1 is showed the universal bind of exchange system to robotic arms and end effector (Kostal \& Velisek 2008).

\section{AUTOMATED EXCHANGE GRIPPER SYSTEM - AHC}

At Institute of Production systems and Applied Mechanics is solved the project VEGA 1/0163/10 Fixture devices in intelligent manufacturing systems. In the frame of this project an automated end effector exchange system is one of the tasks. The actions of finding, identificating and exchanging the needed griper is a task for the device control system. We chose the gripper exchange system AHC (Auto Hand Changing System series MA3). This system is powered by pressed air and the correct binding between AHC unit and gripper with flange are realized by conical shape in the unit adapter.(MA310-AM5) Fig.2, Fig.3.

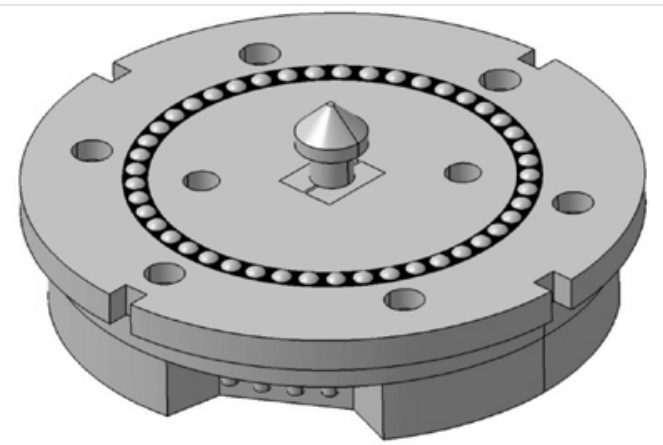

Fig. 2.Transition adapter MA310 -AM5 


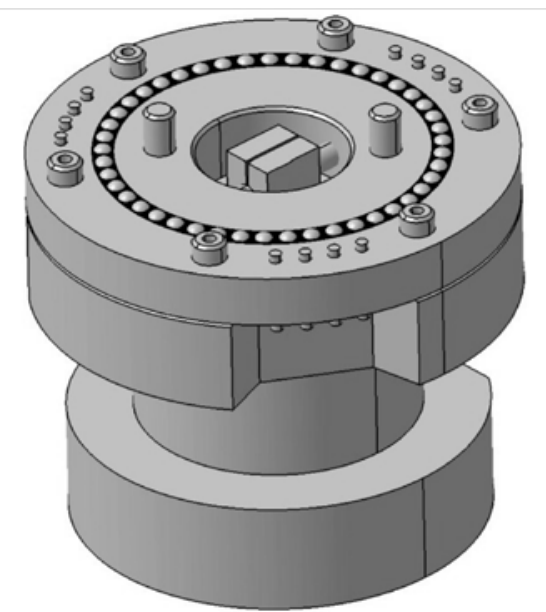

Fig. 3. AHC unit MA311-YNM5

The grippers are assembled into unit adapter by the screws Fig.4. The pressed air and electrical signal bridge is realized too.

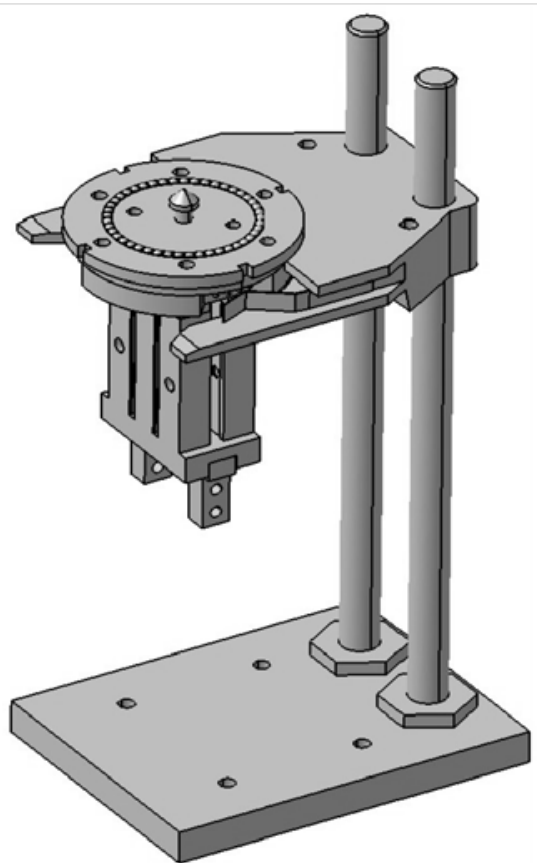

Fig. 4. Stand holder adapter and gripper

The correct binding between AHC unit and a unit adapter with a gripper is shoved at Fig.5. The gripper identification we would like realize by using of one wired identification chips. Every holder must have its own chip reader and every adapter will be equipped by this chip.

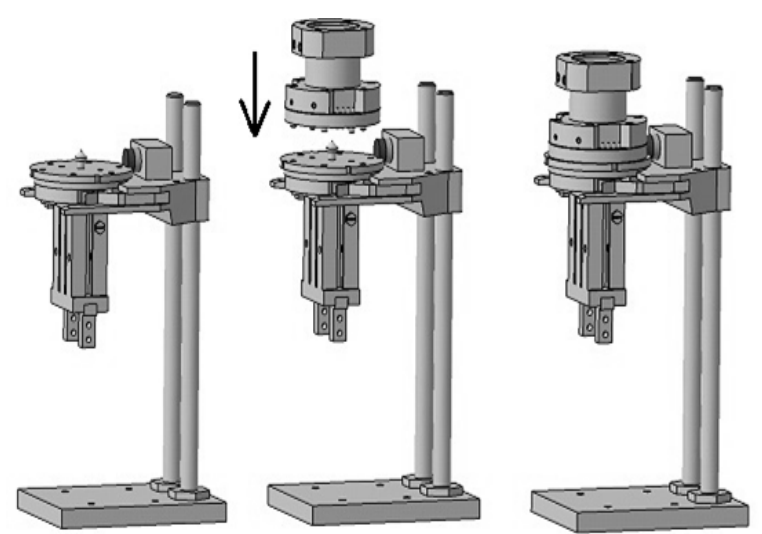

Fig. 5. Visual simulation of automatic exchange gripper

\section{CONCLUSIONS}

Lately it is required a high focus on the technical development in all industry and production areas, since the development in production and automation production in industry advance very quickly. The basic objective of improving and increasing the efficiency of flexible manufacturing - assembly cell is the continuing expansion peripherals. Among the prominent support of extending the intelligence of the system include various sensors, switches and so forth. The new trend of flexible systems is used various exchange periphery. One possibility is the use of automatic exchange gripper included suitably jaws. Automatic exchange systems can assist in increasing reliability of some operations. These types of systems are generally extension input / output elements such as various sensors and control units. Sensor equipment was selected following information, about the communication and signal transmission. Industrial PC is a major means of evaluation and managing the whole inteligent system.

\section{ACKNOWLEDGEMENT}

This paper was created thanks to the national grants: VEGA 1/0163/10 Fixture devices in intelligent manufacturing systems

\section{REFERENCES}

Danisova, N.; Ruzarovsky, R. \& Velisek, K. (2011): Design methodology of automation equipment and control system in the intelligent assembly cell. In: Applied Mechanics and Materials. - ISSN 1660-9336. - Vol. 58-60, s. 2407-2412

Danisova, N., Velisek, K. \& Kostal, P. (2009): Automated tool changing system in the intelligent manufacturing and assembly cell. In: ISCCC 2009 : Proceedings of the 2009 International Symposium on Computing, Communication and Control, October 9-11, 2009, Singapore. - Singapore : International Association of Computer Science and Information Technology Press, - ISBN 978-9-8108-3815-7. - S. 1-8

Matusova, M., Javorova, A. (2008): Modular clamping fixtures design for unrotary workpieces. In: Annals of Faculty of Engineering Hunedoara - Journal of Engineering. - ISSN 1584-2673. - Tom VI, Fasc 3, s. 128-130

Mudrikova, A.; Velisek, K. \& Kostal, P. (2009): Clamping fixtures used for intelligent assembly systems. In: ISCCC 2009: Proceedings of the 2009 International Symposium on Computing, Communication and Control, October 9-11, 2009, Singapore. - Singapore: International Association of Computer Science and Information Technology Press, 2009. - ISBN 978-9-8108-3815-7. - S. 9-15

Kostal, P., Velisek, K. \& Zvolensky, R. (2008): Intelligent Clamping Fixture in General. In: Lecture Notes in Computer Science. - ISSN 0302-9743. - Vol. 5315 : Intelligent Robotics and Applications. First International Conference, ICIRA 2008, Wuhan, China, October 15-17, 2008. Part II. - ISBN 978-3-540-88516-0, s. 459-465

Kostal, P. \& Velisek, K., (2008): Flexible manufacturing cell's clamping fixture. In: Proceedings of the 9th Biennial ASME Conference on Engineering Systems Design and Analysis (ESDA2008) : Haifa, Israel, 7.-9.7.2008. - : ASME, 2008. ISBN 0-7918-3827-7. - CD Rom

Velisek, K., Kostal, P. \& Zvolensky, R. (2008): Clamping Fixtures for Intelligent Cell Manufacturing. In: Lecture Notes in Computer Science. - ISSN 0302-9743. - Vol. 5315 : Intelligent Robotics and Applications. First International Conference, ICIRA 2008, Wuhan, China, October 15-17, 2008. Part II. - ISBN 978-3-540-88516-0, s. 966-972 